\title{
Peningkatan Literasi Media dan Pelatihan Pengelolaan Website Sekolah Di SMP Negeri 2 Kalimanah
}

\author{
Yogiek Indra Kurniawan*1, Nur Chasanah² ${ }^{2}$, Nofiyati³, Arkham Zahri Rakhman4 \\ 1,2,3Informatika, Fakultas Teknik, Universitas Jenderal Soedirman, Indonesia \\ ${ }^{4}$ Teknik Informatika, Institut Teknologi Sumatera, Indonesia \\ *e-mail: yogiek@unsoed.ac.id ${ }^{1}, \underline{\text { nur.chasanah@unsoed.ac.id }}^{2}$, nofiyati@unsoed.ac.id ${ }^{3}$,
} arkham@if.itera.ac.id ${ }^{4}$

\begin{abstract}
Abstrak
Sekolah Menengah Pertama Negeri (SMP N) 2 Kalimanah adalah sebuah sekolah lanjutan pertama yang berada di daerah Kalimanah, Purbalingga. Berdasarkan observasi serta wawancara yang telah dilakukan, terdapat permasalahan di Sekolah tersebut, yaitu mengenai kurangnya pengetahuan mengenai literasi media serta pengelolaan konten website dari para guru di sekolah tersebut. Tujuan kegiatan ini adalah memberikan pelatihan pembuatan konten website maupun literasi media agar sekolah dapat mandiri dalam mengelola website sekolah. Kegiatan pengabdian terbagi menjadi beberapa tahap, yaitu need assessment, pelatihan konten website dan literasi media, serta follow up kepada guru SMP N 2 Kalimanah. Hasil kegiatan ini adalah guru-guru dapat memahami mengenai cara pengelolaan konten website serta mendapatkan peningkatan literasi media.
\end{abstract}

Kata kunci: Guru, Literasi Media, SMP Negeri 2 Kalimanah, Website.

\section{Abstract}

Sekolah Menengah Pertama Negeri (SMP N) 2 Kalimanah is a secondary school located in the Kalimanah area, Purbalingga. Based on observations and interviews that have been conducted, there are problems at the school, namely regarding the lack of knowledge about media literacy and management of website content from teachers. The purpose of this activity is to provide training in website content creation and media literacy so that schools can independently manage the school website. The service activities are divided into several stages, namely need assessment, training on website content and media literacy, and follow-up to teachers of SMP N 2 Kalimanah. The result of this activity is that teachers can understand how to manage website content and get increased media literacy.

Keywords: Media literacy, SMP Negeri 2 Kalimanah, Teacher, Website

\section{PENDAHULUAN}

Sekolah Menengah Pertama Negeri (SMP N) 2 Kalimanah adalah sebuah sekolah menengah tingkat pertama yang berada di daerah Kalimanah, Purbalingga, Jawa Tengah yang terletak di Jalan Mayor Jendral Sungkono km. 3 Desa kalimanah Wetan Kabupaten Purbalingga. Sekolah ini menampung siswa yang umumnya berada di sekitar daerah tersebut. Lokasi SMP N 2 Kalimanah sangat dekat dengan kampus Fakultas Teknik Universitas Jenderal Soedirman, berjarak sekitar 1,6 KM dan dapat ditempuh hanya dalam 4 menit perjalanan menggunakan kendaraan bermotor.

SMPN 2 Kalimanah saat ini telah mengalami kemajuan yang pesat. Mulai dari fisik bangunan, fasilitas pendidikan yang memadai, halaman parkir yang luas, serta penunjang sistem pembelajaran di sekolahan ini. Jumlah peserta didik di sekolah ini termasuk dalam golongan banyak, yaitu 756 siswa yang terbagi dalam 3 angkatan, yaitu kelas 7, kelas 8 dan kelas 9, dengan rata-rata setiap angkatan adalah sebanyak 250 siswa. Sekolah ini mempunyai keunggulan di banding sekolahan yang lain mulai dari penunjang pendidikan yang semakin ditingkatkan seperti laboratorium, sarana olahraga, dan perpustakaan. Luas lahan sekolah sebesar 9840 meter menjadikan sekolah ini mencukupi untuk kegiatan pendidikan siswanya.

Berdasarkan wawancara kepada Bapak Sri Widadi selaku Kepala Sekolah dan observasi yang telah dilakukan di SMP N 2 Kalimanah, terdapat permasalahan di sekolah tersebut yang dapat didefinisikan, yaitu Guru dan staf tendik memiliki kekurangan literasi dalam membangun Web yang komunikatif. Guru dan staf tendik kurang memiliki kemampuan untuk mengisi konten 
serta mengembangkan blog maupun website yang dimiliki sekolah dikarenakan ketidak tahuan guru tersebut terhadap teknologi blog, literasi terhadap media atau pengelolaan website tersebut.

Dalam papernya, [1] menyatakan bahwa dengan adanya aplikasi berbasis komputer, pekerjaan manusia dapat menjadi lebih mudah dalam berbagai bidang kehidupan. Hal ini termasuk dalam penyebaran informasi untuk sekolah. Sehingga untuk mengatasi permasalahan persebaran informasi dan pembuatan media yang efektif, aplikasi berbasis komputer dapat digunakan sebagai solusi.

Beberapa penelitian telah memperlihatkan bahwa aplikasi berbasis komputer dapat diaplikasikan untuk membantu berbagai aspek dalam kehidupan manusia[2], [3]. Lebih khususnya, aplikasi berbasis komputer dapat membantu dalam dunia pendidikan[4]-[8]. Selain itu, aplikasi komputer berbasis website telah terbukti dapat membantu perusahaan untuk menjadi lebih efektif dan efisien[9]-[12]. Pengembangan aplikasi website yang tepat dapat juga membantu pegawai menjadi lebih mudah dalam mengelola pekerjaannya[13], [14].

Website menjadi sebuah alternatif baru dalam segala bidang, salah satunya ditunjukkan oleh paper [15] yang menggunakan website untuk usaha ekonomi simpan pinjam. Dengan adanya website, segala kerumitan manual dapat diselesaikan dengan baik. Pada paper [12], [16], telah dibangun sebuah website informasi sekolah yang dapat mengakomodasi penyebaran informasi di sekolah tersebut dan menjadi media efektif untuk pertukaran informasi antara pihak sekolah maupun pihak luar sekolah. Apabila sekolah dapat mengelola website dengan baik, maka website akan menjadi media promosi yang baik.

Literasi media dari pengguna teknologi baru juga memegang peranan penting ketika ingin menerapkan sebuah teknologi seperti website. Hal ini dibuktikan oleh [17] yang membutuhkan sebuah pelatihan literasi informasi untuk tenaga perpustakaan dan guru agar meningkatkan pengetahuan literasi digital dari guru dan tenaga perpustakaan di wilayah Jakarta Pusat. Paper [18] juga memberikan pelatihan literasi media kepada guru PAUD di kecamatan Cicalengka, sehingga guru-guru tersebut memiliki pengetahuan lebih dalam memberikan pengajaran dalam bentuk media alternatif yang lain.

Literasi media juga memegang peranan yang penting untuk perkembangan informasi pada sebuah instansi, sebagaimana ditunjukkan oleh [19] bahwa guru PAUD dapat juga mencari sumber dan bahan pembelajaran melalui internet dan literasi media yang lain.

Tujuan kegiatan ini adalah untuk memberikan pelatihan pengelolaan website dan literasi media kepada guru-guru di SMP Negeri 2 Kalimanah. Pada kegiatan [20] menegaskan mengenai pentingnya pelatihan serta pemaparan. Dengan pelatihan, tingkat pengetahuan terhadap teknologi baru akan dapat meningkat sehingga pengguna teknologi dapat mempergunakan aplikasi dengan baik dan benar. Dengan adanya pelatihan, pengetahuan peserta dapat ditingkatkan, walaupun pada awalnya peserta pelatihan tidak memiliki pengetahuan mengenai apa yang diberikan pada pelatihan.

\section{METODE}

Metode serta langkah-langkah yang dilakukan dalam menyelesaikan kegiatan ini terdiri dari 3 kegiatan, yaitu:

\subsection{Need Assessment}

Pada langkah ini dilakukan analisis terhadap situasi pada mitra. Analisis situasi adalah hal yang perlu dilakukan pertama kali ketika menghadapi sebuah problem[21]. Metode yang dilakukan adalah dengan FGD (Focus Discussion Group) dengan kepala sekolah maupun guru untuk mengidentifikasi kebutuhan dari sekolah. Setelah itu, dijabarkan permasalahan yang muncul pada mitra, yaitu mengenai kurangnya literasi media dan kurangnya pengetahuan dari guru mengenai pengelolaan website. Dari permasalahan yang muncul, dilakukan analisis lebih lanjut mengenai solusi yang ditawarkan, yaitu pelatihan teknologi website dan literasi media. 


\subsection{Pelatihan Konten Website dan Literasi Media}

Pada langkah ini, dilakukan pelatihan dengan harapan guru-guru yang mengikuti pelatihan ini dapat menggunakan website dengan baik dan benar. Guru yang mengikuti pelatihan nantinya akan menjadi admin bagi website tersebut, sehingga diharapkan guru tersebut dapat melakukan update informasi, promosi serta menyebarkan berita maupun kegiatan-kegiatan sekolah dengan lebih baik.

Isi pelatihan adalah hal-hal yang berkaitan dengan teknologi website dan literasi media. Isi pelatihan tersebut antara lain :

1. Cara penggunaan website, dengan tujuan agar guru maupun staf dapat menggunakan website, baik secara fitur maupun fungsionalitas dari web tersebut.

2. Cara pengelolaan website, dengan tujuan agar website dapat berjalan secara dinamis dan berkembang mengikuti teknologi yang ada.

3. Cara pembuatan konten serta literasi media, dengan tujuan agar keberlangsungan website dapat berjalan dengan baik.

\subsection{Follow Up}

Pada tahap terakhir ini, dilakukan follow up kepada guru-guru di sekolah berupa tindak lanjut mengenai pelatihan kepada guru di SMP N 2 Kalimanah, sehingga apabila guru yang mengikuti pelatihan tidak berada di sekolah, dapat digantikan oleh guru lain yang mengerti tentang website sekolah dan literasi.

\section{HASIL DAN PEMBAHASAN}

Kegiatan pelatihan dilakukan kepada guru yang nantinya menjadi administrator untuk mengurusi website sekolah. Pelatihan diperlukan untuk transfer ilmu dari satu pihak ke pihak yang lainnya[20]. Kegiatan pendampingan dilaksanakan pada hari Senin, tanggal 21 September 2020. Kegiatan tersebut dilakukan secara offline di Lab Komputer SMP Negeri 2 Kalimanah. Pelatihan dihadiri oleh 10 orang guru SMP N 2 Kalimanah.

Metode yang digunakan dalam pemaparan tersebut adalah pelatihan serta tanya jawab secara langsung. Trainer menjelaskan mengenai cara menggunakan website beserta cara pengaturan seluruh konten dari website. Setelah itu, peserta diminta untuk mencoba mempraktekkan secara langsung setiap menu dan fungsionalitas yang telah diajarkan. Alokasi waktu untuk kegiatan pendampingan ini disajikan dalam tabel 1.

Tabel 1. Alokasi Waktu untuk Kegiatan Pendampingan

\begin{tabular}{ccc}
\hline No & Kegiatan & Alokasi Waktu \\
\hline 1 & Pembukaan & 5 Menit \\
2 & Sesi 1: Pelatihan Menu Website Informasi SMP N 2 Kalimanah & 60 Menit \\
3 & Sesi 2: Pelatihan Literasi Media & 60 Menit \\
4 & Penutupan & 5 Menit \\
\hline
\end{tabular}

Kegiatan pelatihan sesi 1 dan 2 dapat ditunjukkan oleh gambar 1 . Sesi 1 diisi oleh Yogiek Indra Kurniawan, sedangkan sesi 2 diisi oleh Nofiyati.

Dengan adanya pelatihan tersebut, maka guru yang menjadi administrator dari website sekolah akan mengetahui setiap fitur, menu, serta cara penggunaan dari website tersebut. Selain itu, guru juga dapat meningkatkan literasi masing-masing terhadap media.

Setelah pelatihan, guru-guru juga mencoba untuk mempraktekkan cara pengelolaan website sekolah serta membuat berita di website sekolah. Berdasarkan observasi yang dilakukan, 10 Guru yang mengikuti pelatihan telah dapat membuat berita di website sekolah dengan baik. Hal tersebut membuktikan bahwa pelatihan telah berhasil meningkatkan pengetahuan guru mengenai pengelolaan website sekolah serta berhasil meningkatkan literasi media dari guru-guru di SMP Negeri 2 Kalimanah. 


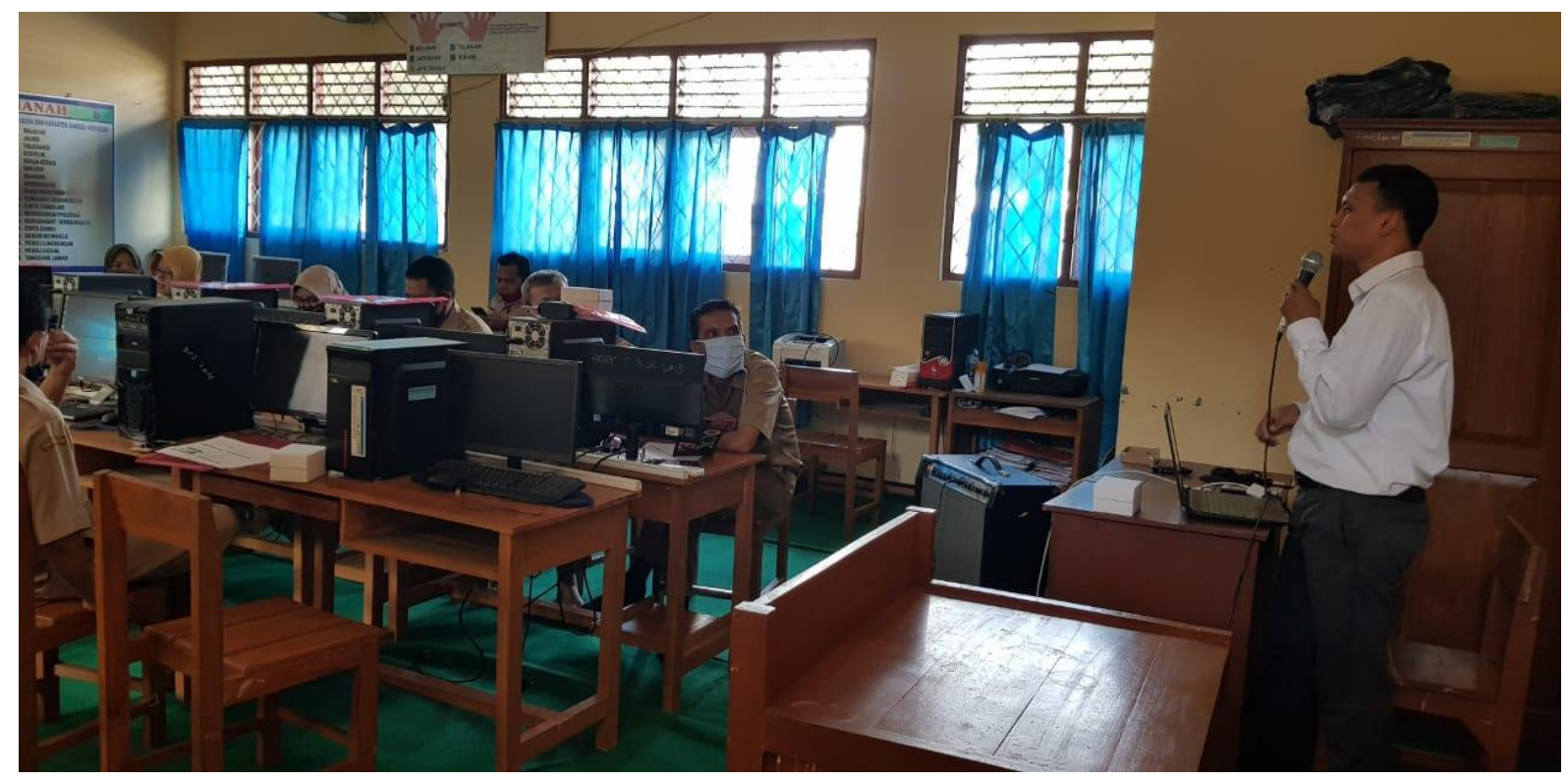

Gambar 1. Pelaksanaan Kegiatan Pelatihan Sesi 1

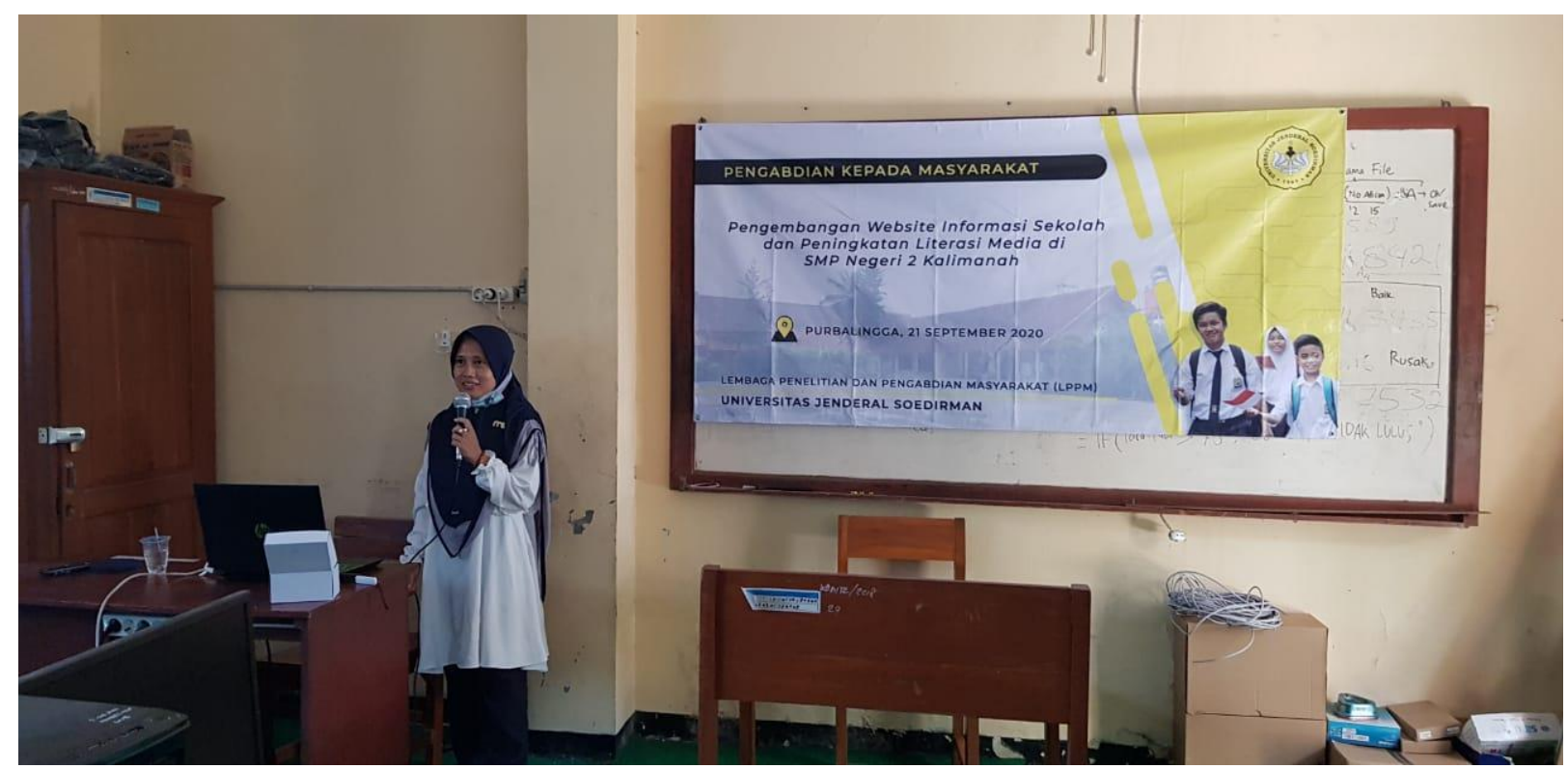

Gambar 1. Pelaksanaan Kegiatan Pelatihan Sesi 2

\section{KESIMPULAN}

Berdasarkan kegiatan pelatihan yang telah dapat diambil kesimpulan bahwa guru-guru sudah dapat melakukan pengelolaan website serta terdapat peningkatan literasi terhadap media bagi guru-guru di SMP Negeri 2 Kalimanah.

\section{UCAPAN TERIMA KASIH}

Ucapan terima kasih kami berikan kepada Sekolah Menengah Pertama Negeri 2 Kalimanah sebagai tempat kegiatan pengabdian masyarakat ini serta kepada Lembaga Penelitian dan Pengabdian Masyarakat (LPPM) Universitas Jenderal Soedirman sebagai penyandang dana pada kegiatan pengabdian masyarakat ini. 


\section{DAFTAR PUSTAKA}

[1] Y. I. Kurniawan and W. Dwiyatmika, "Aplikasi diagnosa retardasi mental pada anak," in Prosiding SEMNAS Penguatan Individu di Era Revolusi Informasi, 2017, pp. 336-343, [Online]. Available: https://publikasiilmiah.ums.ac.id/handle/11617/9053.

[2] Y. I. Kurniawan and P. A. Windiasani, "Sistem Pendukung Keputusan Untuk Penentuan Kelolosan Beasiswa Sekolah Menengah Kejuruan (SMK) menggunakan Metode Fuzzy," J. Tek. Elektro, vol. 9, no. 1, pp. 13-17, 2017, doi: 10.15294/jte.v9i1.9322.

[3] Y. I. Kurniawan and T. I. Barokah, "Klasifikasi Penentuan Pengajuan Kartu Kredit Menggunakan K-Nearest Neighbor," J. Ilm. Matrik, vol. 22, no. 1, pp. 73-82, 2020, doi: 10.33557/jurnalmatrik.v22i1.843.

[4] F. Y. Al Irsyadi, R. Annas, and Y. I. Kurniawan, "Game Edukasi Pembelajaran Bahasa Inggris untuk Pengenalan Benda-Benda di Rumah bagi Siswa Kelas 4 Sekolah Dasar," J. Teknol. dan Inf., vol. 9, no. 2, pp. 78-92, 2019, doi: 10.34010/jati.v9i2.1844.

[5] F. Y. Al Irsyadi, D. Puspitassari, and Y. I. Kurniawan, "ABAS (Ayo Belajar Sholat) : Game Edukasi Pembelajaran Sholat Untuk Anak Tuna Rungu Wicara," J. Manaj. Inform., vol. 9, no. 1, pp. 17-28, 2019, doi: 10.34010/jamika.v9i1.1537.

[6] F. Y. Al Irsyadi, S. Supriyadi, and Y. I. Kurniawan, "Interactive educational animal identification game for primary schoolchildren with intellectual disability," Int. J. Adv. Trends Comput. Sci. Eng., vol. 8, no. 6, pp. 3058-3064, 2019, doi: 10.30534/ijatcse/2019/64862019.

[7] A. S. Haris, S. Fadli, and A. Tantoni, "Sistem Manajemen Lembaga Penelitian Dan Pengabdian Kepada Masyarakat Berbasis Web," J. Manaj. Inform. dan Sist. Inf., vol. 2, no. 1, pp. 28-35, 2019, doi: 10.36595/misi.v2i1.76.

[8] Y. I. Kurniawan and A. F. S. Kusuma, "Aplikasi Augmented Reality Untuk Pembelajaran Salat Bagi Siswa Sekolah Dasar," J. Teknol. Inf. dan Ilmu Komput., vol. 8, no. 1, 2021.

[9] F. S. Sulaeman and I. H. Permana, "Sistem Monitoring Penerapan Rencana Anggaran Biaya Berbasis Web," J. IKRA-ITH Teknol., vol. 5, no. 1, pp. 24-31, 2021.

[10] H. Rubedo, H. Suwandi, and S. Mauluddin, "Sistem Informasi Pertanian Berbasis Kecerdasan Buatan," J. Manaj. Inform., vol. 10, no. April, pp. 84-95, 2020, doi: 10.34010/jamika.v10i1.

[11] D. A. Anggoro and Y. E. A. Lukmana, "Sistem Informasi Pengelolaan Data Nilai Siswa Pada Sd Negeri Jambangan 1 Kabupaten Ngawi," Dinamik, vol. 24, no. 2, pp. 102-112, 2019, doi: 10.35315/dinamik.v24i2.7405.

[12] Y. I. Kurniawan, N. Chasanah, and Nofiyati, "Pengembangan Website Informasi Sekolah di SMP Negeri 2 Kalimanah , Purbalingga," J. Solma, vol. 09, no. 02, pp. 335-346, 2020, doi: http://dx.doi.org/10.22236/solma.v9i2.5440.

[13] D. Gunawan, I. A. Ar Raniri, R. N. Setyawan, and Y. D. Prasetya, "Web-Based Library Information System in Madrasah Ibtidaiyah Negeri Surakarta," J. Tek. Inform., vol. 2, no. 1, pp. 33-41, 2021, doi: 10.20884/1.jutif.2021.2.1.44.

[14] R. E. D. Ramadhana and A. Fatmawati, "Sistem Informasi Manajemen Keuangan Di Pondok Pesantren Adh-Dhuha," J. Tek. Inform., vol. 1, no. 2, pp. 93-99, 2020.

[15] R. Kurniati, F. Ratnawati, and F. P. Putra, "Penerapan Aplikasi Rencana Angsuran Pembayaran Pada Usaha Ekonomi Desa Simpan Pinjam Sungai Alam Berbasis Web," J. Panrita Abdi, vol. 2, no. 2, pp. 165-173, 2018.

[16] Y. I. Kurniawan, "PEMBANGUNAN WEBSITE INFORMASI SEKOLAH DI SMA NEGERI KERJO , KARANGANYAR,” J. Pengabdi. Kpd. Masy., vol. 2, no. 1, pp. 71-84, 2018.

[17] I. Kurnianingsih, R. Rosini, and N. Ismayati, "Upaya Peningkatan Kemampuan Literasi Digital bagi Tenaga Perpustakaan Sekolah dan Guru di Wilayah Jakarta Pusat Melalui Pelatihan Literasi Informasi," J. Pengabdi. Kpd. Masy. (Indonesian J. Community Engag., vol. 3, no. 1, pp. 61-76, 2017.

[18] E. Saepudin and N. A. Damayani, "Literasi Media Bagi Guru Paud Di Kecamatan Cicalengka," Dharmakarya, vol. 5, no. 1, 2016.

[19] A. Hapsari, R. Novitasari, and H. Wahyuningsih, "Pelatihan Literasi Sumber dan Bahan 
Belajar di Internet bagi Guru PAUD di Kecamatan Ngaglik, Sleman," J. Pengabdi. Pada Masy., vol. 3, no. 2, pp. 135-140, 2018.

[20] Y. I. Kurniawan, "Pelatihan Aplikasi Pengukuran Minat Kejuruan Siswa Bagi Guru Sekolah Menengah Kejuruan (SMK) Se-Jawa Tengah," War. LPM, vol. 19, no. 2, pp. 149-155, 2017, doi: $10.23917 /$ warta.v19i2.2224.

[21] A. Ahmad and Y. I. Kurniawan, "Sistem Pendukung Keputusan Pemilihan Pegawai Terbaik Menggunakan Simple Additive Weighting," J. Tek. Inform., vol. 1, no. 2, pp. 101-108, 2020, doi: https://doi.org/10.20884/1.jutif.2020.1.2.14. 